\section{Use of Fusidic Acid for Desquamative Gingivitis Treatment: 1-YearFollow-Up}

Fábio Renato Manzolli Leite, Gustavo Giacomelli Nascimento, Flávio

Fernando Demarco, Janine Waechter, Adriana Etges
Post-graduation Program in Dentistry, Dental School, UFPel - Universidade Federal de Pelotas, Pelotas, RS, Brazil

Correspondence: Dr. Fábio Renato Manzolli Leite, Rua Gonçalves Chaves, 457, sala 511, Centro, 96015-560 Pelotas, RS, Brasil. Tel: +55-53-32256741. email: leite.fabio@gmail.com
This study evaluated retrospectively the effect of fusidic acid on the management of desquamative gingivitis (DG). The study population consisted of 15 patients with DG. Patients were requested to make topical application of 2\% fusidic acid ointment 4 times a day for 6 weeks. Clinical assessments were recorded at baseline, at 6 weeks and 12 months after beginning the therapy. Patients' examination involved lesion size area, pain score and impact on daily activities. All patients presented lesions in maxilla; in 9 patients $(60.0 \%)$ lesions were predominately at the anterior region and $6(40.0 \%)$ at the posterior region of maxilla. Treatment significantly $(p<0.05)$ reduced the pain intensity (from $5.4 \pm 1.12$ to $1.16 \pm 0.97$ ) and its periodicity (from $53.33 \%$ with pain $>3 x$ /week to $13.33 \%)$, and the lesion size in $72.47 \%( \pm 4.12)$ immediately after 6 weeks of treatment. Improvements were sustained for 12 months compared to baseline $(p<0.001)$. It also reduced the impact of disease in daily activities (eating and oral hygiene performance), and improved the emotional condition of patients, who reported better social relationships and habits. Topical application of fusidic acid may be a possible alternative local palliative therapy for desquamative gingivitis treatment.
Key Words: periodontal healing, periodontal immunology, inflammation, desquamative gingivitis

\section{Introduction}

Desquamative gingivitis (DG) is the clinical manifestation of several disorders usually immunologically mediated. This manifestation is characterized by the presence of erythema, erosion and blistering of the attached and marginal gingiva (1). It is a non-plaque-induced gingival symptom (2) associated to muco-cutaneous disorders ranging from immune-mediated vesiculobullous diseases to allergies (3). DG is usually related with oral lichen planus, oral lichenoid lesions, mucous membrane pemphigoid, pemphigus vulgaris, linear immunoglobulin A disease, lupus erythematosus, among others (4).

Since most of these systemic diseases are chronic, and DG is a term indicating a peculiar clinical picture and not a diagnosis per se, the management of this condition is a great challenge to dental clinicians (5). In addition, usually not only the oral cavity is affected by these diseases, but also skin and other extraoral muco-cutaneous sites, like nasal, conjunctiva, larynx and genital mucosa. Systemic drug therapy is often required for these underlying diseases, especially when associated with pemphigus vulgaris (6). Patients present periods of remission and exacerbation, and it might heal after several months or the condition persists for years. Therefore, some authors treat DG lesions with topical corticosteroids when the systemic related disease is under control and in cases of extraoral lesions, systemic steroids are the main choice (7). Nevertheless, the lack of adherence of the topical drug to the affected sites for a long time may reduce efficacy of the treatment $(5,8)$.

Petersen and Thomsen (9) suggested the use of fusidic acid cream in the treatment of plasma cell gingivitis resulting in DG. Fusidic acid is a tetracyclic triterpenoic acid with a primary steroid structure. It is known to exhibit not only antibacterial activity, an important property to avoid opportunistic infection on these affected sites, but also an expressive cytokine-suppressive effect, such as suppression of IL-2, $\gamma$-interferon, IL-1 and IL-6 (10). The use of fusidic acid has been proposed since both systemic and topical corticotherapy may increase susceptibility to bacterial and fungal infections, blood pressure, glycaemia, fluid retention, and adrenal cortex suppression $(4,6,11,12)$.

Since the use of fusidic acid also reduces inflammation markers intimately linked to $D G$, our hypothesis was that topical $2 \%$ fusidic acid ointment may be used as a treatment of desquamative gingivitis. Consequently, the aim of our study was to evaluate the efficacy of fusidic acid as a palliative treatment for DG by evaluating clinical and subjective parameters.

\section{Material and Methods}

Study Design and Participants

Patients' records with DG that used fusidic acid for its palliative treatment with follow-up of at least 12 months were obtained at the Center of Diagnosis of Oral Diseases from the Federal University of Pelotas ( $n=18$ records). All of them were referred to the university to control 
the oral signs and symptoms of DG by their physicians. Two records of patients that used systemic immune modulating agents, e.g. corticosteroids, concomitant to fusidic acid therapy were excluded. Thus, throughout the 6-week treatment with fusidic acid patients were not under systemic treatment for any immune mediated disease due to their physician's recommendation. The study was approved by the Federal University of Pelotas Institutional Ethics Committee (224/2011). This was an open-label investigation.

\section{Diagnosis}

DG was defined by the presence of erythematous and erosive gingivitis involving marginal and/or attached gingiva, absence of destructive periodontal disease as defined by the presence of a site with a periodontal probing depth of $5 \mathrm{~mm}$ or more in combination with clinical attachment loss of $2 \mathrm{~mm}$ or more. More details are available elsewhere (5).

The diagnosis of DG included a detailed medicaldental history, a self-reported personal and family history of systemic diseases, a comprehensive clinical oral examination of lesion and contiguous tissues (13).

Oral mucosal specimens were obtained from the periphery of the lesion so that all of them had some attached epithelium. If the lesions appeared to be lichenoid the specimens were taken from the striated area. Erosive lesions were biopsied from the periphery of the lesion, again to include some attached epithelium (14). Diagnosis of DG was clinical (including presence of erosive or vesiculobullous gingival lesions and lesions in other parts of the body) and histologic as previously described (5). A single pathologist examined all patients and their biopsy slides. In case of doubt another pathologist was contacted to discuss the case.

Oral lichen planus was characterized by a dense sub-epithelial lympho-histiocytic infiltrate, increased intra-epithelial lymphocytes and degeneration of basal keratinocytes. Slides were also analyzed for the presence of parakeratosis, acanthosis, and for fibrinogen and fibrin deposition in a linear pattern in the basement membrane zone.

In cases of mucous membrane pemphigoid the disease was described by separation at basal membrane level, giving rise to a subepithelial blister. The lamina propria presented a chronic inflammatory infiltrate composed of eosinophils, lymphocytes and neutrophils. Direct immunofluorescent techniques revealed the presence of homogeneous $\lg \mathrm{G}$ and $\mathrm{C} 3$-complement deposits along the junction between the connective tissue and epithelium.

For the pemphigus vulgaris intercellular edema was identified in the suprabasal portion of the stratum spinosum, with the formation of clefts and acantholysis, leading to the formation of blisters. Direct immunoflurescence was used to confirm the diagnosis. It revealed marks on the epithelial cell surface, indicating presence of immunoglobulin $\mathrm{G}(\mathrm{IgG})$ deposits on the keratinocyte membrane.

\section{Treatment}

All patients received periodontal therapy including oral hygiene instructions, full-mouth scaling and root planing with hand instruments (Hu-Friedy, Chicago, IL, USA), at least 4 weeks before fusidic acid therapy as periodontal treatment has demonstrated to improve the results of DG (5).

\section{Patient Examination}

The same investigator performed the interviews and clinical examinations at all time points. During interviews patients were asked to determine their pain intensity, which was registered (15) (0 to 10 scores). Attenuating and exacerbating pain factors, frequency of pain (daily, weekly, monthly or occasionally), type of pain (spontaneous or stimulated) and frequency of oral hygiene were also recorded. The impact of the disease in daily activities, in the last six months was assessed in terms of frequency and severity (16). Daily activities were considered as follows: eating, performing oral hygiene, influence on mood (e.g., irritation, sadness, and others) and social interaction with other people.

The initial and final areas of lesions were recorded with a caliper rule (Western, São Paulo, SP, Brazil), measuring the largest length and height of the lesion in centimeters. Patients received a fusidic acid 2\% ointment (Neo Química, Anápolis, GO, Brazil) for 5-min applications four times a day during six weeks. The area was gently dried with clean gauze and a small portion of the ointment applied with the fingers covering the whole lesion. As any other agent used for DG control, the ointment presents no specific adhesive agent, so patients were instructed to remain seated and expectorate excess of saliva after application, moreover they were asked not to remove the remains of the ointment from their mouth and/or spit for at least 10 min. Patients were advised not to swallow the medication, and to avoid eating and drinking for 60 min after mouth rinsing. According to the manufacturer, no adverse effect has been reported with the use of fusidic acid, but patients were controlled by clinical examination and phone contact regarding local and dermal eruptions, itch, nausea, pain, headache, among others. Authors had access to patients' hematological exams to analyze possible interference of ointment usage with blood parameters. Self-reported patient compliance was 100\%. 
Patients were followed with weekly appointments for 6 weeks. After that, patients were monitored with monthly appointments during 12 months. Patients were informed to return whenever lesion or pain reappeared.

Data were tabulated twice and descriptive and statistical analyses were carried out using the Stata 11.0 software package (StataCorp LP; College Station, TX, USA). In order to evaluate drug effects on pain, size lesion and associated factors, repeated measures ANOVA with posthoc tests were employed. For statistical significance, a $p$-value of $p<0.05$ was considered.

\section{Results}

Demographic characteristics of patients are described in Table 1 including age, gender, associated disease and frequency of oral hygiene. The mean age was 55.2 years, ranging from 39 to 76 years, and females ere more affected than males. DG was associated with oral lichen planus in seven (46.67\%) patients. Pemphigus vulgaris was the second most common cause $(n=5,33.33 \%)$. The remaining five patients presented mucous membrane pemphigoid. When questioned in relation to oral hygiene habits, most of the patients mentioned brushing teeth at least twice a day despite the pain, but four of them brushed their teeth once a day because of pain. All of them had already changed their toothbrushes from medium or soft to extra-soft bristles after lesion development, also due to pain. In addition, in previous dental appointments their toothpastes had already been changed to kids' toothpaste without significant effect. No attenuating factor was mentioned, and citric or acid substances usually exacerbated the lesions and pain. All patients presented lesions in maxilla; in 9 patients $(60.0 \%)$ lesions were predominately on the anterior region and 6 $(40.0 \%)$ on the posterior region of maxilla. In all patients' records, the previous use of corticosteroids reduced the signs and symptoms of DG.

Data of reported pain are summarized in Table 2. Fusidic acid reduced the pain score, periodicity, type and lesion size, when compared with baseline at 6 weeks and 12 months $(p<0.001)$ (Fig. 1). The lesion area was significantly smaller when compared with baseline. The percentage of

Table 1. Demographic characteristics of participants

\begin{tabular}{lc}
\hline Age (in years) & 55.2 (range 39 to 76) \\
\hline Gender & $13(86.67 \%)$ \\
Female & $2(13.33 \%)$ \\
Male & \\
Diagnostic & $7(46.67 \%)$ \\
Oral lichen planus & $5(33.33 \%)$ \\
Pemphigus vulgaris & $3(20.0 \%)$ \\
Mucous membrane pemphigoid & \\
Oral hygiene & $11(73.34 \%)$ \\
twice a day & $4(26.66 \%)$ \\
$\quad$ once a day &
\end{tabular}

Table 2. Comparison of pain quality and percentage of lesion reduction ${ }^{\S}$

\begin{tabular}{lccc}
\hline Variable & Baseline & 6-week & 12 -month \\
\hline Pain score (mean \& SD) & $5.4 \pm 1.12^{\mathrm{A}}$ & $1.16 \pm 0.97^{\mathrm{B}}$ & $2.11 \pm 0.98^{\mathrm{C}}$ \\
$\begin{array}{l}\text { Periodicity of pain } \\
>3 x / \text { week }\end{array}$ & $8(53.33 \%)^{\mathrm{A}}$ & $2(13.33)^{\mathrm{B}}$ & $3(20.0)^{\mathrm{B}}$ \\
$\quad<3 \times /$ week & $7(46.67 \%)$ & $13(86.67)$ & $12(80.0)$ \\
Type of pain & & & \\
$\quad$ Spontaneous & $7(46.66)^{\mathrm{A}}$ & $1(6.67)^{\mathrm{B}}$ & $2(20.0)^{\mathrm{B}}$ \\
$\quad$ Stimulated & $8(53.33)$ & $14(93.33)$ & $13(80.0)$ \\
\% lesion reduction (mean \& SD) & $0.00 \% 0^{\mathrm{A}}$ & $72.47 \%( \pm 4.12)^{\mathrm{B}}$ & $60.12 \%( \pm 3.76)^{\mathrm{B}}$ \\
\hline
\end{tabular}

$\$$ Different uppercase letters in a row mean statistical differences within the different follow-up periods (comparison of baseline, 6-week and final results).
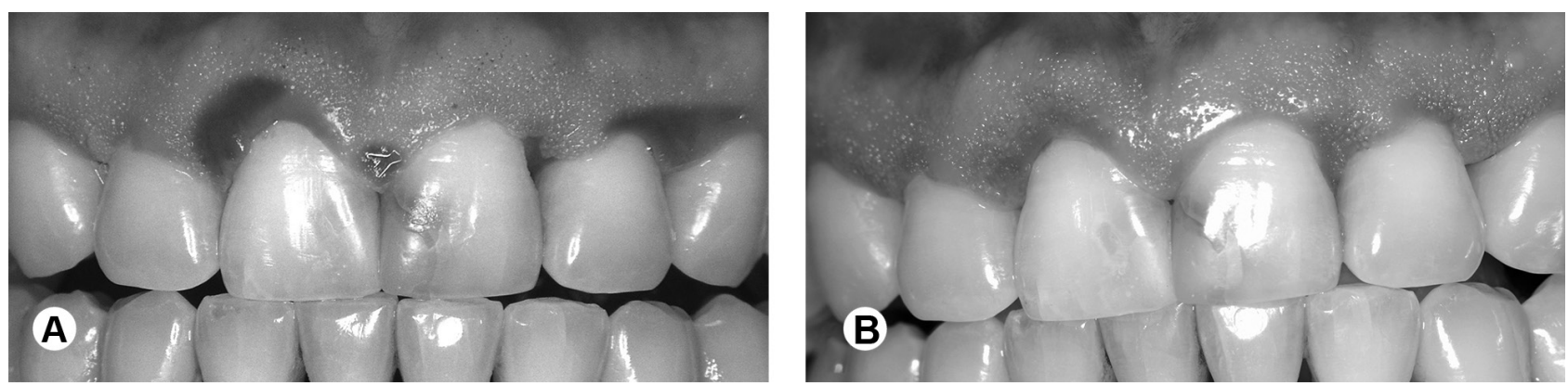

Figure 1. Case of DG in upper arch treated with fusidic acid initial. A: initial. B: 12 months after treatment. 
lesion size reduction remained constant in the fusidic acid group from 6 weeks to 12 months $(62.47 \%$ and $60.12 \%$, respectively). Pain frequency and severity experienced in daily activities were recorded and presented in Table 3 . All patients reported some kind of impact in daily activities caused by the gingival condition. Compared with baseline, the treatment decreased pain experience values at 6

Table 3. Comparison of pain frequency and severity during daily activities between baseline and the different time points ${ }^{\S}$

\begin{tabular}{lccc}
\hline Variable & Baseline & 6 -week & 12-month \\
\hline Eating & & & \\
Frequency & & $1(6.67)^{\mathrm{B}}$ & - \\
$\quad$ Rare & - & $14(93.33)$ & $15(100.0)^{\mathrm{B}^{\text {*** }}}$ \\
Moderate & - & - & - \\
High & $15(100.0)^{\mathrm{A}}$ & & \\
Severity & & $07(46.67)^{\mathrm{B}}$ & $06(40.0)^{\mathrm{B}^{\text {*** }}}$ \\
Low & - & $08(53.33)$ & $09(60.0)$ \\
Moderate & $05(33.33)^{\mathrm{A}}$ & - & - \\
High & $10(66.67)$ & &
\end{tabular}

Hygiene

$\begin{array}{lccc}\begin{array}{l}\text { Frequency } \\ \text { Rare }\end{array} & - & 09(60.0)^{\mathrm{B}} & - \\ \text { Moderate } & - & 06(40.0) & 15(100.0)^{\mathrm{C}^{* *}} \\ \text { High } & 15(100.0)^{\mathrm{A}} & - & - \\ \text { Severity } & & & \\ \text { Low } & - & 14(93.33)^{\mathrm{B}} & 06(40.0)^{\mathrm{C}} \\ \text { Moderate } & 15(100.0)^{\mathrm{A}} & 01(6.67) & 09(60.0) \\ \text { High } & - & - & -\end{array}$

Emotional

$\begin{array}{lccc}\begin{array}{l}\text { Frequency } \\ \text { Rare }\end{array} & 04(26.67)^{\mathrm{A}} & 08(53.33)^{\mathrm{B}} & 07(46.67)^{\mathrm{B}^{*}} \\ \text { Moderate } & 07(46.67) & 07(46.67) & 08(53.33) \\ \text { High } & 04(26.67) & - & - \\ \text { Severity } & & & \\ \text { Low } & 05(33.33)^{\mathrm{A}} & 12(80.0)^{\mathrm{B}} & 11(73.33)^{\mathrm{B}^{*}} \\ \text { Moderate } & 07(46.67) & 03(20.0) & 02(13.33) \\ \text { High } & 03(20.0) & & 02(13.33)\end{array}$

${ }^{*} p<0.05 ;{ }^{* * *} p<0.001 .{ }^{\S}$ Different uppercase letters in a row means statistical differences within the different follow-up waves (comparison of baseline, 6 -week and final results). weeks and at 12 months, with better results in all aspects. One patient reported an allergy to the medication and discontinued the use of the ointment.

\section{Discussion}

This study aimed to analyze the clinical performance of a topical treatment for management of desquamative gingivitis over 1-year retrospective follow-up. Based on the results above, the tested hypothesis was confirmed, as the fusidic acid presented similar results in the short and the long term.

In literature, a lack of studies with more than 6 months follow-up of desquamative gingivitis management is observed. To the best of the authors' knowledge there is only one clinical trial using topical therapy in patients with $D G$, but the patients were followed up for 6 weeks only (7). Nevertheless the response to topical therapies of desquamative oral lesions in gingiva is frequently favorable in short time evaluations, lacking reliability in a longer term.

Data of this study suggested that fusidic acid could be used for palliative treatment of desquamative gingivitis' oral manifestation. Different factors have been implicated in mucous membrane lesions worsening. Performing a critical review of the literature, most of these factors are still speculative, like dietary factors (use of cinnamon, mint, peppermint and chewing gum), flavored toothpastes, herpes simplex infection, neoplastic processes and allergens (17). In this report, the patients reported avoiding use of these dietary factors. Participants were using kids' toothpaste due to less abrasion, flavor and coloring compounds; also, they were using extra-soft toothbrushes to reduce epithelial removal.

The comparison of lesions' severity at baseline and at the end of the study showed that patients presented a significant improvement of clinical signs and symptoms. Fusidic acid is an anti-inflammatory drug, which inhibits interleukin-2 and interferon-gamma production, T-lymphocyte proliferation and protein synthesis by avoiding ribosome translocation to the messenger RNA (17). Thus, fusidic acid tends to present a more localized and less immunosuppressive activity than the use of corticosteroids, such as clobetasol and dexamethasone.

Gonzalez-Moles et al. (18) reported that the use of topical corticosteroid clobetasol propionate in ulcerative or erosive oral lesions could cause side effects, such as moon face and facial hair. Moreover, its use should be controlled in the oral cavity, as candidiasis is the most common side effect in mouth (19). Thus, this type of treatment should be closely monitored since most of the patients used the corticosteroid up to three weeks. Some reports verified that adrenal suppression might occur 
as early as $24 \mathrm{~h}$ after initiating topical corticotherapy $(20,21)$, even though it is not commonly seen in topical applications. In this study, no side effects were observed with topical use of dexamethasone and one patient presented some kind of allergy to fusidic acid with small ulcerations in lip mucosa in direct contact with the treated area.

Patients were asked in the interview some questions from a shorter version of the specific-condition OIDP instead of the generic version. According to Bernabe et al. (16) specific oral health related quality of life measures emphasis on a precise condition, which makes them useful in assessing particular attributes. In addition, their narrower focus makes them potentially more sensitive to small but clinically important changes in oral health. About improvements in quality of life after treatments, there is only a case report in literature demonstrating that basic functions, such as eating, chewing, social and psychological factors had a significantly improvement after treatment of DG (22). Even with an increase of pain experience values in the 12-month period, patients were more satisfied about their oral condition when compared with baseline.

It is important to highlight, that even with incomplete healing of lesions in some cases, treatment resulted in better quality of life for ordinary functions, like eating. Fusidic acid therapy produced complete healing in five patients only, but no erosive area could be observed in the remaining patients. Oral epithelium covered the entire lesion and only a slight erythema could be observed. Since DG is a manifestation of a systemic condition, it is not uncommon to return or exacerbate when the underlying systemic disease is not under control. A close relationship with patient's physician with information exchange is required.

As any clinical report some limitations apply also to this one. In every clinical situation with self-applied medication, authors cannot be sure that patients used it correctly. In addition, different systemic diseases have relationship with $D G$ and might be a confounding factor influencing the final results. Thus, sample and a prospective follow-up should be expanded in order to assure the efficacy of fusidic acid use as a palliative therapy. New studies should address a control placebo group or a gold standard medication for comparison, and an adhesive agent could be incorporated to the ointment to verify if the lack or reduced response in some cases could be due to ointment removal by saliva. The main problem with including these groups relies on ethics of not offering treatment to relief pain and the time and money required to enroll all these patients in a prospective study for a quite rare condition.
Even though this is a limited sample of open label clinical data, it suggests that the topical application of $2 \%$ fusidic acid in desquamative gingivitis lesions seems to be able to reduce its size. Further clinical investigations are necessary in order to evaluate this therapy in the long term.

\section{Resumo}

Este estudo avaliou retrospectivamente o efeito do ácido fusídico sobre o manejo da gengivite descamativa (DG). A população do estudo consistiu de 15 pacientes com DG. Os pacientes foram solicitados a fazer aplicação tópica de pomada de ácido fusídico $2 \% 4$ vezes ao dia, durante 6 semanas. As avaliações clínicas foram registradas no início do estudo, em 6 semanas e 12 meses após o início da terapia. 0 exame dos pacientes envolveu tamanho da área da lesão, intensidade da dor e impacto nas atividades diárias. Todos os pacientes apresentaram lesões na maxila; em 9 pacientes $(60,0 \%)$ as lesões foram predominantemente na região anterior e em 6 $(40,0 \%)$ na região posterior da maxila. 0 tratamento significantemente $(p<0,05)$ reduziu a intensidade da dor (de $5,4 \pm 1,12$ para $1,16 \pm 0,97)$ e a sua periodicidade (de $53,33 \%$ com dor $>3 x /$ semana para $13,33 \%$ ), e 0 tamanho da lesão em $72,47 \%( \pm 4,12)$ imediatamente após 6 semanas de tratamento. As melhorias foram sustentadas por 12 meses, quando comparado aos valores iniciais $(p<0,001)$. Também reduziu o impacto da doença nas atividades diárias (alimentação e desempenho de higiene oral), e melhorou a condição emocional dos pacientes, que relataram melhores relações e hábitos sociais. A aplicação tópica de ácido fusídico pode ser uma alternativa para terapia local paliativa no tratamento de gengivite descamativa.

\section{References}

1. Lo Russo L, Guiglia R, Pizzo G, Fierro G, Ciavarella D, Lo Muzio L, et al.. Effect of desquamative gingivitis on periodontal status: a pilot study. Oral Dis 2010;16:102-107.

2. Armitage GC. Development of a classification system for periodontal diseases and conditions. Ann Periodontol 1999;4:1-6.

3. Suresh L, Neiders ME. Definitive and differential diagnosis of desquamative gingivitis through direct immunofluorescence studies. J Periodontol 2012;83:1270-1278.

4. Lo Russo L, Fedele S, Guiglia R, Ciavarella D, Lo Muzio L, Gallo P, et al.. Diagnostic pathways and clinical significance of desquamative gingivitis. J Periodontol 2008;79:4-24.

5. Guiglia R, Di Liberto C, Pizzo G, Picone L, Lo Muzio L, Gallo PD, et al.. A combined treatment regimen for desquamative gingivitis in patients with oral lichen planus. J Oral Pathol Med 2007;36:110-116.

6. Motta AC, Domaneschi C, Komesu MC, Souza C da S, Aoki V, Migliari DA. Double-blind, crossover, placebo-controlled clinical trial with clobetasol propionate in desquamative gingivitis. Braz Dent J 2009;20:231-236.

7. Corrocher G, Di Lorenzo G, Mansueto P, Martinelli N, Esposito-Pellitteri M, Gelio S, et al.. Comparison of topical tacrolimus $0.1 \%$ in pectin ointment with clobetasol $0.5 \%$ ointment in adults with moderate to severe desquamative gingivitis: A 4-week, randomized, double-blind clinical trial. Clin Ther 2006;28:1296-1302.

8. Nisengard RJ, Rogers RS, 3rd. The treatment of desquamative gingival lesions. J Periodontol 1987;58:167-172.

9. Petersen CS, Thomsen K. Fusidic acid cream in the treatment of plasma cell balanitis. J Am Acad Dermatol 1992;27:633-634.

10. Bendtzen K, Diamant M, Faber V. Fusidic acid, an immunosuppressive drug with functions similar to cyclosporin A. Cytokine 1990;2:423429.

11. Lozada-Nur F, Huang MZ, Zhou GA. Open preliminary clinical trial of clobetasol propionate ointment in adhesive paste for treatment of chronic oral vesiculoerosive diseases. Oral Surg Oral Med Oral Pathol 1991;71:283-287.

12. Voute $A B$, Schulten EA, Langendijk PN, Kostense PJ, van der Waal I. 
Fluocinonide in an adhesive base for treatment of oral lichen planus. A double-blind, placebo-controlled clinical study. Oral Surg Oral Med Oral Pathol 1993;75:181-185.

13. Rees TD. Vesiculo-ulcerative diseases and periodontal practice. J Periodontol 1995;66:747-748.

14. Yih WY, Maier T, Kratochvil FJ, Zieper MB. Analysis of desquamative gingivitis using direct immunofluorescence in conjunction with histology. J Periodontol 1998;69:678-685.

15. Likert R. A technique for the measurement of attitudes. New York, 1932.

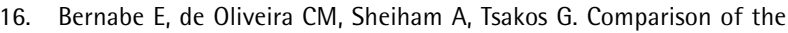
generic and condition-specific forms of the Oral Impacts on Daily Performances (OIDP) Index. J Public Health Dent 2009;69:176-181.

17. Mahler $\mathrm{V}$, Hornstein OP, Kiesewetter F. Plasma cell gingivitis: treatment with 2\% fusidic acid. J Am Acad Dermatol 1996;34:145-146.

18. Gonzalez-Moles MA, Morales P, Rodriguez-Archilla A, Isabel IR, Gonzalez-Moles S. Treatment of severe chronic oral erosive lesions with clobetasol propionate in aqueous solution. Oral Surg Oral Med Oral Pathol Oral Radiol Endod 2002;93:264-270.

19. Scully C, Gorsky M, Lozada-Nur F. The diagnosis and management of recurrent aphthous stomatitis: a consensus approach. J Am Dent Assoc 2003;134:200-207.

20. Kirketerp M. Systemic effects of local treatment with fluocinolone acetonide applied under plastic film. Acta Dermato-Venereol 1964;44:54-58.

21. Plemons JM, Rees TD, Zachariah NY. Absorption of a topical steroid and evaluation of adrenal suppression in patients with erosive lichen planus. Oral Surg Oral Med Oral Pathol 1990;69:688-693.

22. Saito A, Makiishi T. Chronic desquamative gingivitis and oral healthrelated quality of life. J Dermatol Case Rep 2009;3:47-49.

Received September 4, 2014 Accepted May 22, 2015 